\title{
Toxic Interactions of Romiplostim and Rituximab in Normal and Thrombocytopenic Rats
}

\author{
Saeed H. ${ }^{1 *}$, Sayed H.M. ${ }^{1}$, Ramadan A. ${ }^{2}$ and Nahla S. Kotb ${ }^{3}$ \\ ${ }^{1}$ Department of Pharmacology and Toxicology ${ }^{1}$, Faculty of Pharmacy, Cairo University, Egypt. \\ ${ }^{2}$ Department of Pharmacology, Faculty of Veterinary, Cairo University, Egypt. \\ ${ }^{3}$ Department of Biochemistry, National Organization for Research and Control of Biologicals, Egypt. \\ * Corresponding author: Saeed H., email: hamedeitch@ hotmail.com
}

\begin{abstract}
Immune thrombocytopenia (ITP) is an autoimmune disorder characterized by immunologic destruction of normal platelets and insufficient production of platelets mediated by autoantibodies. And there are different treatment options for management of thrombocytopenia according to each case. Because of the progression of the disease and its multiple pathophysiological pathways a combination of treatments used for management of ITP would be a point of interest. Co-administration of therapies may be useful in patients who are refractory to monotherapies and may result in a booster response because they target multiple mechanisms. Romiplostim is a potent drug used for the management of acute ITP and can be administered with other treatment options for ITP. The combination of Rituximab and Romiplostim may inhibit platelet destruction and at the same time increase platelet production. This combination can lead to a strong and a massive increase in platelet counts. In preclinical studies of Romiplostim safety margins could not be reliably estimated. Although some post marketing surveillance studies provided some information about the safety profile of this drug. More information is needed to evaluate drug interactions between Romiplostim and Rituximab.The goal of this study is to investigate the safety of cotreatment of Romiplostim with Rituximab as compared to each of these drugs in normal rats and thrombocytopenic rats. The measured safety parameters were evaluated for liver and kidney functions in normal and diseased groups of rats.The safety of this regimen should be taken in consideration, so that a balance between the harmful effects and beneficial response could be attained. Future studies are necessary to investigate the safety and efficacy balance of Romiplostim and Rituximab alone or in combination with each other for management of thrombocytopenia.
\end{abstract}

Keywords: Immune thrombocytopenia (ITP), Rats, Romiplostim, Rituximab and Thrombopoietin Receptor Agonists (TPO-RAs).

Original Article:

https://dx.doi.org/10.21608/javs.2019.2 $\underline{0470.1000}$

Received 03 Dec.,2019

Accepted 21 Dec., 2019

Published in 9 Jan., 2020

This is an open access article under the term of the Creative Commons Attribution $\quad 4.0 \quad$ (CC-BY) International License. To view a copy of this license, visit http://creativecommons.org/licenses /by/4.0/

J. Appl. Vet. Sci.,5 (1):1-10.

\section{INTRODUCTION}

The disease is most widely accepted the abbreviation, ITP, has variably been defined as "immune thrombocytopenic purpura", "idiopathic thrombocytopenic purpura" and most recently "immune thrombocytopenia". It is an autoimmune disorder characterized by immunologic destruction of otherwise normal platelets most commonly occurring in response to an unknown stimulus. ITP may occur in isolation (primary) or in association with other disorders (secondary).The International Working Group (IWG) defines ITP as newly diagnosed (diagnosis to 3 months), persistent (3 to 12 months from diagnosis), or chronic (lasting for more than 12 months) (Neunert et al., 2011). There are 2 major processes that contribute to ITP: decreased platelet production and increased platelet destruction. Immune thrombocytopenia is associated with several chronic infections including Helicobacter pylori (HP), human immunodeficiency virus (HIV), autoimmune diseases, such as systemic lupus erythematosus (SLE) and 
hepatitis $\mathrm{C}$ virus (HCV). The supposed mechanism is molecular mimicry, resulting in cross-reactive antibodies between bacterial and platelet antigens (Raj, 2017).

Romiplostim, the thrombopoietin Receptor Agonists (TPO-RAs), has been approved for patients with chronic ITP who had an insufficient response to corticosteroids, immunoglobulins, or splenectomy. TPO-RAs work by activating TPO receptors on megakaryocytes and inducing platelet production via the JAK2 and STAT5 kinase pathways (Zufferey $\boldsymbol{e t}$ al., 2017). A global pharmacovigilance program is underway to fully understand the real and potential adverse events with long-term use of Romiplostim. The most common Romiplostim-related serious adverse events reported from several prospective clinical trials suggests were thrombocytopenia, increased bone marrow reticulin, myocardial infarctions, neurological events and venous thrombotic events (Aboulafia and Vishnu, 2016) .

In the animal safety studies, Romiplostim produced a dose-dependent increase in bone marrow fibrosis and hyperostosis, which decrease when therapy is discontinued (Kuter et al., 2009). The most common adverse effects reported were similar in each clinical study group and consisted of headache, fatigue, epistaxis, and arthralgia. Serious adverse events reported were bone marrow reticulin formation, which resolved with discontinuation of Romiplostim, and thromboembolism in a patient with previous history of vascular disease with platelets above baseline but below normal range (Kuter et al., 2008).

Rituximab (Mabthera ${ }^{\circledR}$, Roche), an anti-CD20directed cytolytic monoclonal antibody, works by inhibiting B cells from producing autoantibodies as well as reverting T-cell abnormalities in patients who respond to treatment (Zufferey $\boldsymbol{e t}$ al., 2017). It is used for the treatment of non-Hodgkin's lymphoma, chronic lymphocytic leukemia, and rheumatoid arthritis (RA) in combination with methotrexate in adults with moderately to severely active RA. It is used off-label for the treatment of adults with ITP. Rituximab is reserved for patients with a high bleeding risk who have failed treatment with at least IVIG, anti-D immune globulin, or corticosteroids (Raj, 2017). Rituximab can improve complete platelet count responses by 6 months in patients with immune thrombocytopenia (Chugh et al., 2015).

Major short-term adverse effects of Rituximab include pruritus, urticaria, chills, vomiting, fever, rash, arthralgia, fatigue and serum sickness (Liang et al., 2012). Long-term side effects have also been observed. In patients being treated for more than 12 months, Rituximab has been associated with infections, malignancies, pulmonary embolism, pneumonitis, and central nervous system hemorrhage (Arnold $\boldsymbol{e t}$ al., 2007).

Combination therapies may be useful in patients who are refractory to monotherapies and may result in an enhanced response because they target multiple mechanisms (Chapin et al., 2016). Several studies were concluded the efficacy of coadministration of Romiplostim and Rituximab, as it may inhibit platelet destruction and at the same time increase platelet production. However this regimen can lead to a strong and even overwhelming increase in platelet counts, frequent laboratory examinations and thromboprophylaxis are necessary to prevent adverse reactions such as thrombotic events (Pohlen et al., 2010).

Even so there is still a need for further studies for assessment of safety, efficacy and validation of this combination in a larger number of patients with ITP (Contis et al., 2013). The most common adverse event related to this combination was fever, which was mainly related to the upper respiratory, urinary tract, and gastrointestinal infection. There was an overrepresentation of rash, headache, stomachache, and chest congestion (Zhou et al., 2015). The goal of this study is to investigate the safety of co-treatment of Romiplostim with Rituximab on liver and kidney of rats as compared to each of these drugs.

\section{MATERIALS AND METHODS}

\section{Animals}

Adult male and females albino rats (Spargue Dawely strain) weighing $(150-250 \mathrm{gm})$, were used for the in vivo experiments. They were purchased from the animal colony of the Faculty of Veterinary, Cairo University. Rats were kept under controlled environment at a constant temperature $\left(23 \pm 2{ }^{\circ} \mathrm{C}\right)$, humidity $(60 \pm 10 \%)$ and light/dark (12/12) cycles. Animals were singly housed and acclimatized for one week before any experimental procedures and were allowed standard rat chow and tap water ad libitum. Animal handling and experimental protocols were approved by the Research Ethical Committee of the Faculty of Pharmacy, Cairo University (Cairo, Egypt), and comply with the Guide for the Care and use of Laboratory Animals (Garber, 2010).

\section{Drugs \\ Romiplostim (Nplate $^{\circledR}$ ) is manufactured by Romiplostimen Europe B.V., and was supplied by Multipharma for Pharmacutical\& Chemical productsas vials of two concentrations $250 \mu \mathrm{g}$ and $500 \mu \mathrm{g}$.}

Rituximab (Mabthera ${ }^{\circledR}$ ) is supplied by Hoffman La Roche as vials containing $10 \mathrm{mg} / \mathrm{ml}$. 
Carboplatin "Ebewe" 10mg/ml vial was supplied by Novartis Pharma Company "Sandoz Division" as vial containing concentrated solution of carboplatin 10 $\mathrm{mg} / \mathrm{ml}$.

\section{Experimental design}

Animal dose was calculated according to Paget's table concerning human/animal crossover dose transformation (Paget and Barnes, 1964). The dose of Romiplostim for rats was $6.3 \mu \mathrm{g} / \mathrm{kg}$ based on actual body weight and was administered subcutaneously once weekly. The dose of Rituximab for rats was 9 $\mathrm{mg} / \mathrm{kg}$ based on actual body weight and was administered intravenously once weekly. The experimental design was as follow:

\section{Group I: Normal Rats}

Animals were divided into four subgroups each consisted of 10 rats as follow:

Subgroup 1, untreated control rats received Normal Saline $(1 \mathrm{ml} / \mathrm{kg}$ body wt.) intraperitoneally throughout the experimental period (8 weeks).

Subgroup 2, treated with Romiplostim alone.

Subgroup 3, treated with Rituximab alone.

Subgroup 4, treated subcutaneously with Romiplostim in combination with Rituximab intravenously.

\section{Group II: Thrombocytopenic rat model}

Induction of thrombocytopenia in rats was done by intraperitoneal injection of Carboplatin in a dose $62.5 \mathrm{mg} / \mathrm{kg}$ based on actual body weight per week for two or three weeks (Wang et al., 2011). After the third week of Carboplatin injection, animals was observed and showed weakness and hemorrhages from their anus. There were also significant decreases in platelet count after estimation of their complete blood counts (CBC), which indicated the decrease in the number of platelets that means rats became thrombocytopenic. Then diseased animals were divided into four experimental subgroups as follow:

Subgroup 1, untreated control received distilled water $(1 \mathrm{ml} / \mathrm{kg}$ body $\mathrm{wt}$.) intraperitoneally throughout the experiment period (8 weeks).

Subgroup 2, treated subcutaneously with Romiplostim alone.

Subgroup 3, treated intravenously with Rituximab alone.

Subgroup 4, treated subcutaneously with Romiplostim in combination with Rituximab intravenously.

\section{Sampling}

- The blood samples were collected at intervals of two, four, six and eight weeks throughout the experimental period for different analysis from normal and thrombocytopenic rats.
- Serum samples were separated from the collected blood samples by centrifugation at $3000 \mathrm{rpm}$ for 10 minutes.

- After eight weeks rats were anesthetized with ether, and then sacrificed (by dislocation under ether anesthesia).

\section{Estimation of liver and kidney function parameters in serum}

Kinetic UV test for the quantitative determination of alanine aminotransferase (ALT), aspartate aminotransferase (AST), alkaline phosphatase (ALP), urea, creatinine and uric acid in rat's serum on OLYMPUS AU400 automated chemistry analyzer and located in the Medical Research Center of Excellence in the National Research Center, Egypt. The Olympus analysers automatically compute the creatinine concentration of each sample.

It was carried out according to methods described in the user guide of the device for in vitro diagnostic use only as follow:

i. Estimation of Alanine aminotransferase (ALT) activity in serum was carried out according to the method described by Bergmeyer and Horder (1980).

ii. Estimation of aspartate aminotransferase (AST) activity in serum was carried out according to the method described by SARIS, N.E. (1978).

iii. Estimation of Alkaline phosphatase (ALP) activity in serum was carried out according to the method described by Tietz et al., (1983). [

iv. Estimation of Blood Urea Nitrogen (BUN) level in serum was carried out according to the method described by Talke and Schubert (1965).

v. Estimation of Creatinine level in serum was carried out according to the method described by Cook (1971).

vi. Estimation of Uric acid level in serum was carried out according to the method described by Fossati et al., (1980).

\section{Estimation of complete blood count (CBC)}

The Estimation of complete blood count (CBC) was done by using the Medonic M-Series Hematology Analyzer - Cap Piercing Sampling produced by Boule Medical AB, Stockholm, Sweden and located in the Medical Research Center of Excellence in the National Research Center, Egypt. There was M-series Quick Reference Guide for informing the researcher about the routine procedures for that device. 


\section{A. Normal Group}

\section{RESULTS}

Table 1: Effect of Romiplostim, Rituximab alone and in combination on liver function parameters of normal rats (Mean \pm S.E., $n=10$ ):

\begin{tabular}{|c|c|c|c|c|c|}
\hline Parameter & Time & Control & Romiplostim & Rituximab & Combination \\
\hline & W2 & $44.6 \pm 3.84$ & $46 \pm 3.11$ & $48 \pm 2.02$ & $37.6 \pm 0.51$ \\
\cline { 2 - 6 } & $\mathrm{W} 4$ & $41 \pm 2.28$ & $35.2 \pm 1.66$ & $33.8 \pm 2.06$ & $43.2 \pm 4$ \\
\cline { 2 - 6 } & $\mathrm{W} 6$ & $45 \pm 3.97$ & $45 \pm 2.35$ & $39 \pm 3.32$ & $45.4 \pm 3.85$ \\
\cline { 2 - 6 } & $\mathrm{W} 8$ & $46.2 \pm 4.53$ & $44 \pm 2.43$ & $41.4 \pm 3.71$ & $36.2 \pm 1.28^{@}$ \\
\cline { 2 - 6 } & $\mathrm{W} 2$ & $134.4 \pm 11.13$ & $140 \pm 3.07$ & $138 \pm 3.45$ & $122.8 \pm 3.65$ \\
\cline { 2 - 6 } & $\mathrm{W} 4$ & $99 \pm 6.72$ & $100.6 \pm 9.46$ & $92.8 \pm 7.05$ & $102 \pm 8.85$ \\
\cline { 2 - 6 } AST (IU/L) & $\mathrm{W} 6$ & $107.8 \pm 3.02$ & $107 \pm 4.85$ & $123.8 \pm 3.84$ & $113.2 \pm 6.98$ \\
\cline { 2 - 6 } & $\mathrm{W} 8$ & $109 \pm 8.08$ & $102.8 \pm 8.99$ & $109.2 \pm 9.41$ & $97.6 \pm 7.72$ \\
\hline & $\mathrm{W} 2$ & $130 \pm 8.30$ & $158.6 \pm 14.61$ & $78 \pm 7.58^{*}$ & $164.6 \pm 13.44$ \\
\cline { 2 - 6 } ALP (IU/L) & $\mathrm{W} 4$ & $168 \pm 10.85$ & $182.6 \pm 7.30$ & $209.4 \pm 20.38$ & $369.4 \pm 36.55^{\#}$ \\
\cline { 2 - 6 } & $\mathrm{W} 6$ & $192 \pm 12.24$ & $245.8 \pm 12.72^{\S}$ & $241 \pm 17.17^{\S}$ & $254.6 \pm 22.76^{\S}$ \\
\cline { 2 - 6 } & $\mathrm{W} 8$ & $197.6 \pm 16.40$ & $286.2 \pm 26.54^{@}$ & $181.6 \pm 12.71$ & $153.2 \pm 10.43$ \\
\hline
\end{tabular}

Data was expressed as means of 7-10 animals \pm S.E.M. Two way ANOVA followed by Uncorrected Fisher's LSD multiple comparison test were employed for statistical evaluation of difference among means.

* Significantly different from normal control group at $\mathrm{p}<0.05$ after 2 weeks.

\# Significantly different from normal control group at $\mathrm{p}<0.05$ after 4 weeks.

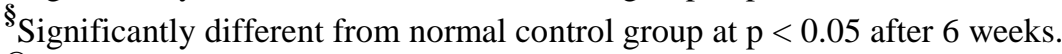

${ }^{@}$ Significantly different from normal control group at $\mathrm{p}<0.05$ after 8 weeks.

Fig. 1: Effect of Romiplostim, Rituximab alone and in combination on liver function parameters of normal rats

Figure 1 (A) : Effect of Romiplostim, Rituxim ab alone and in combination on serum ALT activity of normal rats

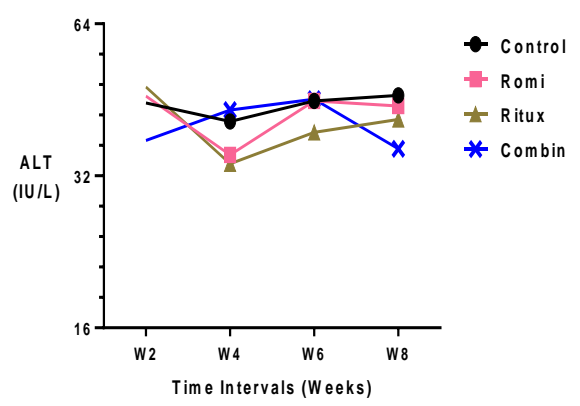

Figure 1 (B) : Effect of Romiplostim, Rituximab alone and in combination on serum AST activity of normal rats

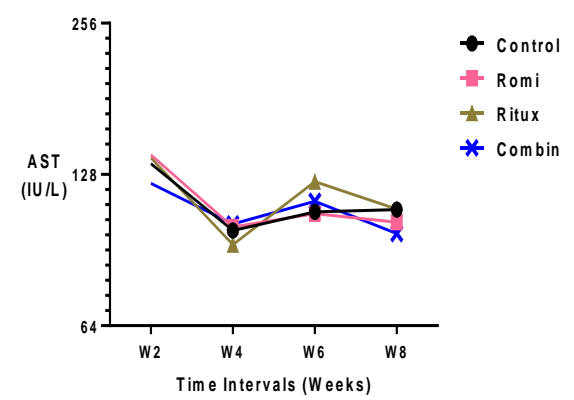

Figure 1 (C) : Effect of Romiplostim, Rituximabalone and in combination on serum ALP activity of normal rats

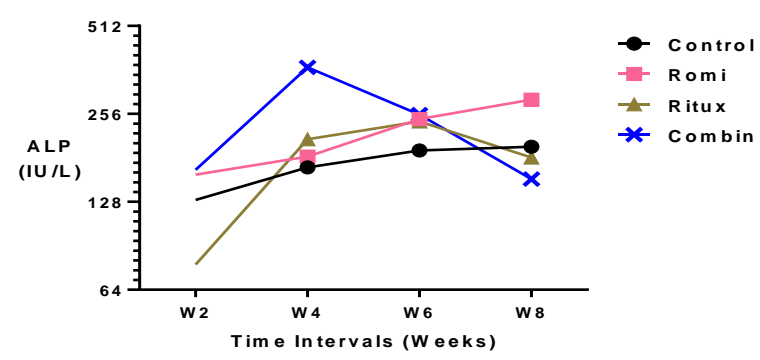


Table 2: Effect of Romiplostim, Rituximab alone and in combination on kidney function parameters of normal rats (Mean \pm S.E., $n=10)$ :

\begin{tabular}{|c|c|c|c|c|c|}
\hline Parameter & Time & Control & Romiplostim & Rituximab & Combination \\
\hline \multirow{4}{*}{ BUN (mg/dl) } & $\mathrm{W} 2$ & $32 \pm 1.48$ & $45.6 \pm 1.33^{*}$ & $37.8 \pm 1.07$ & $31 \pm 0.71$ \\
\cline { 2 - 6 } & $\mathrm{W} 4$ & $30.6 \pm 2.62$ & $35 \pm 2.77$ & $25 \pm 2.43$ & $44 \pm 3.62^{\#}$ \\
\cline { 2 - 6 } & $\mathrm{W} 6$ & $34.2 \pm 1.60$ & $34 \pm 2.59$ & $47 \pm 1.30^{\S}$ & $39 \pm 2.05$ \\
\cline { 2 - 6 } & $\mathrm{W} 8$ & $30.6 \pm 1.81$ & $31.4 \pm 0.93$ & $34.4 \pm 3.17$ & $21.4 \pm 1.96^{@}$ \\
\cline { 2 - 6 } & $\mathrm{W} 2$ & $0.696 \pm 0.02$ & $0.706 \pm 0.03$ & $0.764 \pm 0.03^{*}$ & $0.538 \pm 0.01^{*}$ \\
\cline { 2 - 6 } Creatinine (mg/dL) & $\mathrm{W} 4$ & $0.64 \pm 0.03$ & $0.424 \pm 0.0^{\#}$ & $0.304 \pm 0.02^{\#}$ & $0.444 \pm 0.02^{\#}$ \\
\cline { 2 - 6 } & $\mathrm{W} 6$ & $0.69 \pm 0.02$ & $0.462 \pm 0.02^{\S}$ & $0.542 \pm 0.02^{\S}$ & $0.546 \pm 0.02^{\S}$ \\
\cline { 2 - 6 } & $\mathrm{W} 8$ & $0.67 \pm 0.02$ & $0.542 \pm 0.02^{@}$ & $0.526 \pm 0.04^{@}$ & $0.52 \pm 0.02^{@}$ \\
\hline \multirow{3}{*}{ Uric Acid (mg/dL) } & $\mathrm{W} 2$ & $1.3 \pm 0.09$ & $1.16 \pm 0.05$ & $1.08 \pm 0.04$ & $0.98 \pm 0.09^{*}$ \\
\cline { 2 - 6 } & $\mathrm{W} 4$ & $1.2 \pm 0.06$ & $0.98 \pm 0.09$ & $0.76 \pm 0.05^{\#}$ & $0.86 \pm 0.07^{\#}$ \\
\cline { 2 - 6 } & $\mathrm{W} 6$ & $1.3 \pm 0.1$ & $1.12 \pm 0.10$ & $1.06 \pm 0.09$ & $0.9 \pm 0.07^{\S}$ \\
\cline { 2 - 6 } & $\mathrm{W} 8$ & $0.92 \pm 0.08$ & $1.14 \pm 0.11$ & $0.92 \pm 0.09$ & $0.82 \pm 0.06$ \\
\hline
\end{tabular}

Data was expressed as means of 7-10 animals \pm S.E.M. Two way ANOVA followed by Uncorrected Fisher's LSD multiple comparison test were employed for statistical evaluation of difference among means.

* Significantly different from normal control group at $\mathrm{p}<0.05$ after 2 weeks.

${ }^{\#}$ Significantly different from normal control group at $\mathrm{p}<0.05$ after 4 weeks.

${ }^{\S}$ Significantly different from normal control group at $\mathrm{p}<0.05$ after 6 weeks.

${ }^{\circledR}$ Significantly different from normal control group at $\mathrm{p}<0.05$ after 8 weeks

Fig. 2: Effect of Romiplostim, Rituximab alone and in combination on kidney function parameters (serum BUN level, serum Creatinine activity and serum uric acid content) of normal rats

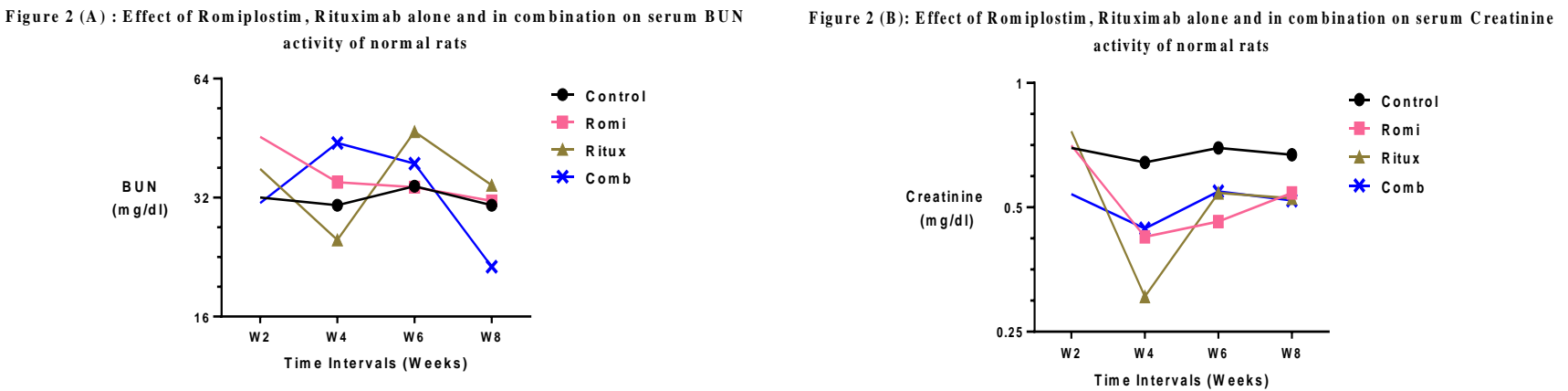

Figure 2 (C) : Effect of Romiplostim, Rituximab alone and in combination on serum Uric Acid content of normal rats

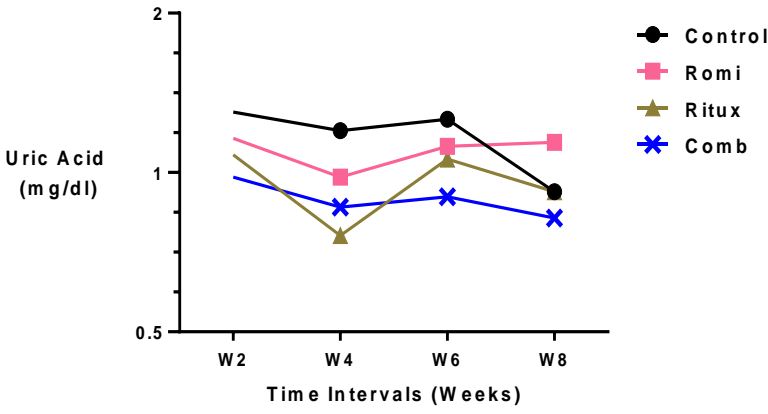




\section{Thrombocytopenic group}

\section{Estimation of platelets count after induction of the disease}

After injection of Carboplatin at a dose $62.5 \mathrm{mg} / \mathrm{kg}$ based on actual body weight per week for three weeks, rats developed profound thrombocytopenia. The means of platelet count were less than 100 x $10^{9} / \mathrm{L}$, while the normal control ranged between $755.8 \pm 13.67 \times 10^{9} / \mathrm{L}$ to $843.8 \pm 55.6 \times 10^{9} / \mathrm{L}$.

Table 3: Effect of Romiplostim, Rituximab alone and in combination on liver function parameters of thrombocytopenic rats (Mean \pm S.E., $n=10$ ):

\begin{tabular}{|c|c|c|c|c|c|}
\hline Parameter & Time & Control & Romiplostim & Rituximab & Combination \\
\hline \multirow{4}{*}{ ALT (IU/L) } & $\mathrm{W} 2$ & $40 \pm 0.71$ & $46.6 \pm 3.49$ & $43 \pm 2.65$ & $39.2 \pm 2.35$ \\
\hline & W4 & $39.6 \pm 3.31$ & $39.8 \pm 3.60$ & $43.6 \pm 3.44$ & $39.6 \pm 3.44$ \\
\hline & W6 & $33.6 \pm 2.32$ & $37.6 \pm 2.82$ & $43.2 \pm 3.43^{\S}$ & $52 \pm 1.30^{\S}$ \\
\hline & $\mathrm{W} 8$ & $45.2 \pm 4.08$ & $38.6 \pm 3.57$ & $38.4 \pm 3.75$ & $54.2 \pm 2.97^{@}$ \\
\hline \multirow{4}{*}{$\begin{array}{c}\text { AST } \\
\text { (IU/L) }\end{array}$} & W2 & $141.4 \pm 6.77$ & $133 \pm 3.0$ & $116.6 \pm 5.16^{*}$ & $110.8 \pm 6.91^{*}$ \\
\hline & W4 & $101.4 \pm 2.20$ & $107.6 \pm 10.48$ & $95.6 \pm 4.50$ & $92.8 \pm 7.14$ \\
\hline & W6 & $103.6 \pm 8.45$ & $99.4 \pm 8.49$ & $115 \pm 5.36$ & $89 \pm 4.15$ \\
\hline & W8 & $103 \pm 4.55$ & $107.8 \pm 8.55$ & $112.6 \pm 4.13$ & $104.8 \pm 8.05$ \\
\hline \multirow{4}{*}{$\begin{array}{c}\text { ALP } \\
\text { (IU/L) }\end{array}$} & $\mathrm{W} 2$ & $341.6 \pm 7.67$ & $180.8 \pm 10.56^{*}$ & $229.2 \pm 22.05^{*}$ & $190 \pm 16.32 *$ \\
\hline & W4 & $237.8 \pm 19.69$ & $191.8 \pm 11.64^{\#}$ & $199.2 \pm 17.25$ & $167.8 \pm 12.06^{\#}$ \\
\hline & W6 & $201.6 \pm 9.26$ & $233.4 \pm 18.95$ & $219.6 \pm 20.19$ & $194.6 \pm 19.31$ \\
\hline & W8 & $194.2 \pm 16.58$ & $122.4 \pm 11.92^{@}$ & $104.2 \pm 10.11^{@}$ & $105.2 \pm 9.92^{@}$ \\
\hline
\end{tabular}

Data was expressed as means of 7-10 animals \pm S.E.M. Two way ANOVA followed by Uncorrected Fisher's LSD multiple comparison test were employed for statistical evaluation of difference among means.

* Significantly different from normal control group at $\mathrm{p}<0.05$ after 2 weeks.

"Significantly different from normal control group at $\mathrm{p}<0.05$ after 4 weeks.

${ }^{\S}$ Significantly different from normal control group at $\mathrm{p}<0.05$ after 6 weeks.

${ }^{\circledR}$ Significantly different from normal control group at $\mathrm{p}<0.05$ after 8 weeks.

Fig. 3: Effect of Romiplostim, Rituximab alone and in combination on liver function parameters of thrombocytopenic rats

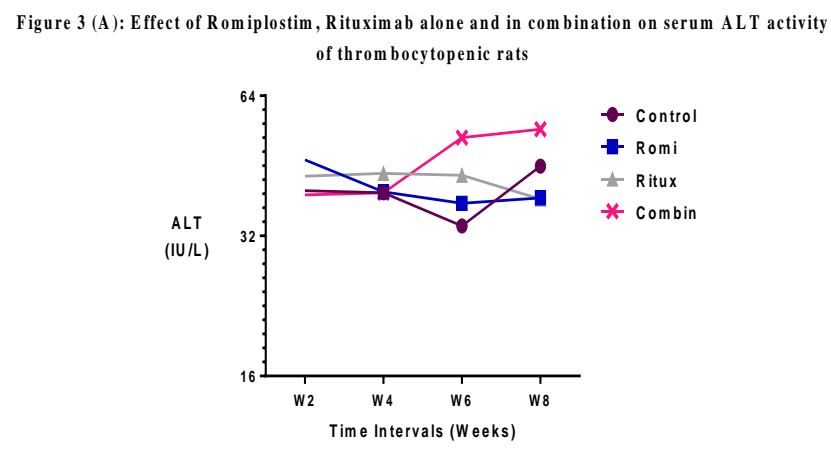

Figure 3 (B) : Effect of Romiplostim, Rituximab alone and in combination on serum AST activity of thrombocytopenic rats
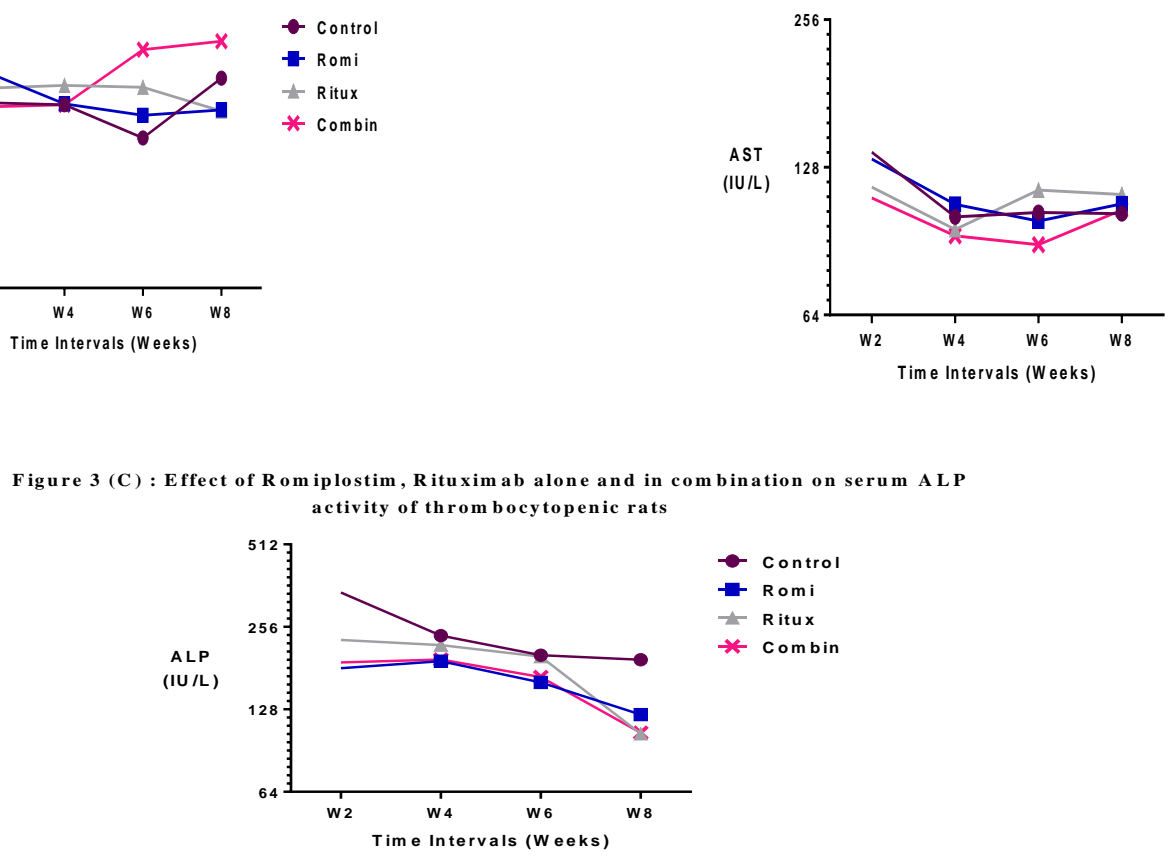

$$
\begin{aligned}
& * \text { Control } \\
& + \text { Romi } \\
& \text { * Ritux } \\
& \text { * Combin }
\end{aligned}
$$


Table 4: Effect of Romiplostim, Rituximab alone and in combination on kidney function parameters of thrombocytopenic rats (Mean \pm S.E., $n=10$ ):

\begin{tabular}{|c|c|c|c|c|c|}
\hline Parameter & Time & Control & Romiplostim & Rituximab & Combination \\
\hline \multirow{4}{*}{ BUN (mg/dl) } & W2 & $29.8 \pm 1.98$ & $26 \pm 0.71$ & $28.8 \pm 2.08$ & $25.4 \pm 1.81$ \\
\hline & W4 & $34.8 \pm 1.59$ & $39 \pm 1.87$ & $43.6 \pm 3.04^{\#}$ & $44 \pm 3.78^{\#}$ \\
\hline & W6 & $29.4 \pm 2.80$ & $33.2 \pm 2.31$ & $30 \pm 2.66$ & $30 \pm 2.30$ \\
\hline & W8 & $27.8 \pm 1.07$ & $10.6 \pm 0.93^{@}$ & $13 \pm 0.71^{@}$ & $27 \pm 1.95$ \\
\hline \multirow{4}{*}{ Creatinine $(\mathrm{mg} / \mathrm{dL})$} & W2 & $0.40 \pm 0.01$ & $0.59 \pm 0.01^{*}$ & $0.6 \pm 0.02^{*}$ & $0.67 \pm 0.06^{*}$ \\
\hline & W4 & $0.44 \pm 0.02$ & $0.54 \pm 0.02^{\#}$ & $0.49 \pm 0.01$ & $0.44 \pm 0.03$ \\
\hline & W6 & $0.42 \pm 0.03$ & $0.46 \pm 0.04$ & $0.49 \pm 0.02^{\S}$ & $0.48 \pm 0.02$ \\
\hline & W8 & $0.49 \pm 0.04$ & $0.59 \pm 0.01^{@}$ & $0.54 \pm 0.03$ & $0.51 \pm 0.01$ \\
\hline \multirow{4}{*}{ Uric Acid (mg/dL) } & W2 & $1.3 \pm 0.1$ & $1.5 \pm 0.14$ & $0.94 \pm 0.10^{*}$ & $1.16 \pm 0.10$ \\
\hline & W4 & $0.96 \pm 0.09$ & $1.26 \pm 0.12^{\#}$ & $0.76 \pm 0.06$ & $0.84 \pm 0.06$ \\
\hline & W6 & $0.76 \pm 0.07$ & $0.86 \pm 0.07$ & $0.74 \pm 0.02$ & $0.64 \pm 0.07$ \\
\hline & W8 & $0.70 \pm 0.07$ & $0.96 \pm 0.07^{@}$ & $0.9 \pm 0.08$ & $0.94 \pm 0.09$ \\
\hline
\end{tabular}

Data was expressed as means of 7-10 animals \pm S.E.M. Two way ANOVA followed by Uncorrected Fisher's LSD multiple comparison test were employed for statistical evaluation of difference among means.

*Significantly different from normal control group at $\mathrm{p}<0.05$ after 2 weeks.

\#Significantly different from normal control group at $\mathrm{p}<0.05$ after 4 weeks.

${ }^{\S}$ Significantly different from normal control group at $\mathrm{p}<0.05$ after 6 weeks.

${ }^{\circledR}$ Significantly different from normal control group at $\mathrm{p}<0.05$ after 8 weeks.

Fig. 4: Effect of Romiplostim, Rituximab alone and in combination on kidney function parameters of thrombocytopenic rats :

Figure 4 (A) : Effect of Romiplostim, Rituximab alone and in combination on serum BUN activity of thrombocytopenic rats

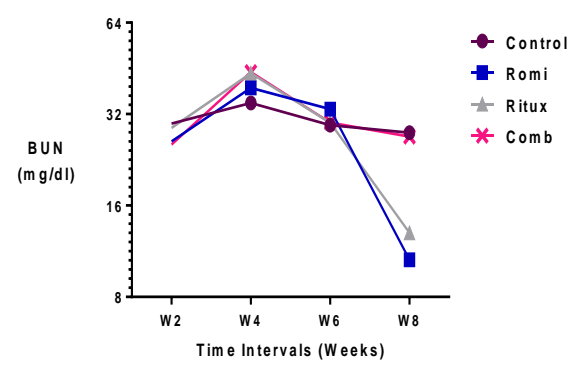

Figure 4 (B) : Effect of Romiplostim, Rituximab alone and in combination on serum Creatinine activity of throm bocytopenic rats

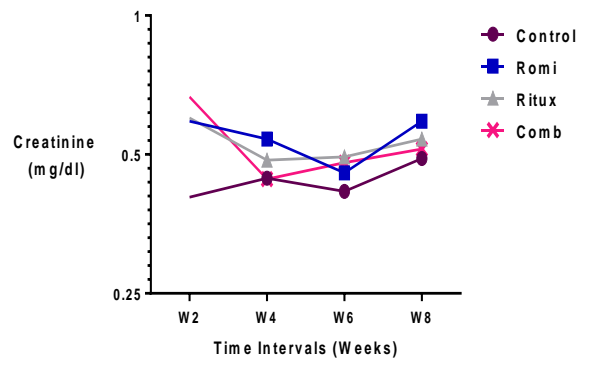

Figure 4 (C) : Effect of Romiplostim, Rituximab alone and in combination on serum Uric Acid content of thrombocytopenic rats

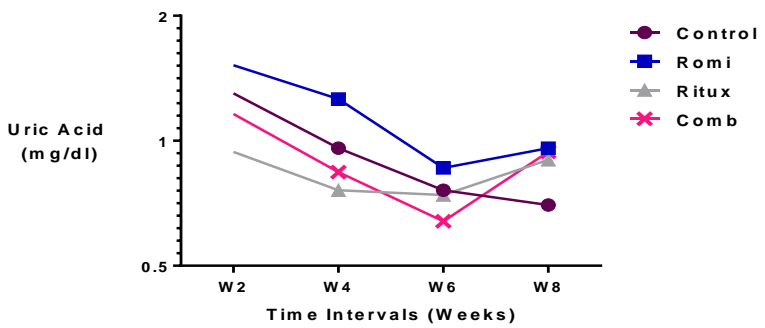




\section{DISCUSSION}

In this study, liver function evaluation revealed that co-administration of both drugs inhibited the activity of alanine aminotransferase enzyme at the end of experiment in normal rats. Thus it seems that both drugs did not affect the liver function either acutely or chronically as revealed shown in Table 1.

However alkaline phosphatase activity (ALP) in serum was inhibited after two weeks of Rituximab alone in this study. This elevation of ALP activity may occur in infiltrative diseases of liver, where spaceoccupying lesions (e.g. tumors) are present. It is also occurs in liver cirrhosis (Gaw et al., 2013). This is obviously an indication of hepatic injury. But there is no evidence of a correlation between administered drugs and the disturbance of ALP activity. Thrombocytopenia was induced by an intraperitoneal injection of carboplatin, This is in accord with other reports as Wang et al., (2011).

Carboplatin induces thrombocytopenia in rats by virtue of its antimitotic effect on stem cells, which leads to decreased platelet production and thrombocytopenia that can potentially be more prolonged and more refractory to treatment (VadhanRaj, 2009). Carboplatin's mechanism of action appears to be related to its ability to cross-link DNA (Ulich $\boldsymbol{e t}$ al., 1995).

In thrombocytopenic rats there were some alterations in liver enzymes as presented shown in Table 3. Six weeks after Rituximab administration significant elevation of ALT activity was observed. Coadministration of both compounds significantly stimulated ALT activity. Elevations of such enzymes also occur in jaundice due to obstruction of the large bile passages, severe hemolysis and mostly occurring when there is liver damage (Varley, 1954). Two weeks after Rituximab administration in this study significant inhibition of AST activity was produced. Coadministration of both compounds significantly suppressed AST activity.

The findings of elevation for ALP of thrombocytopenic suggest that the toxic effect of carboplatin may be reduced after discontinuation of administration. Also it is away from suspicion about the contribution of treatments in elevation of ALP in serum. On the other hand, it is clear from this observation that combination of each agent may have harmful effects on liver enzymes exceeding that of each drug. These findings may be in line with those of Hruban et al., (1991) who found that carboplatin may have also indirectly contributed to liver failure through the complications of thrombocytopenia.Also King and Perry (2001) concluded that chemotherapeutic agents as carboplatin, alone or in combination, may cause hypersensitivity reactions or direct hepatic toxicity, leading to altered drug metabolism leading to increased risk of non-hepatic toxicity. On the other hypothesis, alkaline phosphatase isoenzymes may distinguish between bone and liver disease, especially in patients in whom metastases of bone or liver are suspected (Gaw et al., 2013)

These observations may be strengthened by Cuker (2010) who reported that the treatment-related morbidity associated with thrombopoietic growth factors. Although hepatotoxicity has not been recognized as an adverse event in clinical trials of Romiplostim, the drug has not been tested extensively in patients with hepatic impairment and should therefore be used with caution in this population. Also Janssens (2012) reported that megakaryocyte stimulation by transforming growth factor or TPO induces a dose-dependent marrow fibrosis in rodents. Controversially Bussel et al., (2015) revealed that long-term Romiplostim treatment in small group of patients maintained platelet counts for over 4 years in children with ITP with good tolerability without significant hepatotoxicity.

Further Moussa and Mowafy (2013) monitored a rapid response to Romiplostim therapy in patients with chronic hepatitis $\mathrm{C}$, liver cirrhosis and thrombocytopenia secondary to $\mathrm{HCV}$ infection achieving platelet counts $70 \times 10^{9} / \mathrm{L}$. The findings of Rituximab on liver function parameters are supported by findings of Kashiwagi and Tomiyama (2013) who noted possible occurrence of life-threatening infectious complications, especially in countries, such as Japan, with high incidence of HBV carriage. Also Borker and Choudary (2011) reported a number of serious side effects of Rituximab including hepatitis B reactivation leading to fulminant hepatitis and hepatic failure. Lack of information about the relation of test drugs and liver enzymes makes it hard to interpretate the aforementioned controversial reports.

Interestingly, in the present report the kidney function parameters of normal rats revealed a harmful effect of test drugs on kidney as shown in table 2, as BUN levels were elevated at different weeks after administration of each drug as well as coadministration of both. At the end of experimental period the combination of both drugs diminished the BUN level. Decreases in blood urea have been reported in some cases of severe liver disease. Post renal diseases which lead to increase in the blood urea in which there is obstruction to the flow of urine (e.g. stones in the urinary tract) and if prolonged irreversible kidney damage may occur (Varley, 1954).

Serum creatinine activity was decreased in rats treated with Rituximab alone or combined with Romiplostim. For Romiplostim alone, the serum creatinine activity inhibited at week 4 . Reduction of 
serum creatinine levels occur in severe hepatic diseases, due to the reduced production of creatinine in the liver, reduced muscle mass, and an inadequate intake of protein (Takabatake et al., 1988). Uric acid content of rats treated with both drugs was decreased throughout 6 weeks of treatment period. Rituximab alone decreased serum uric acid content at week 4 only.

Thrombocytopenic rats demonstrated changes in kidney function parameters as shown in table 4. As serum creatinine was declined for all rats induced by carboplatin. Two weeks after Rituximab administration uric acid content was significantly inhibited. On the other hand, four weeks after Romiplostim administration uric acid content was significantly increased, and presented at the end of Romiplostim treatment. The rise in serum uric acid occurs when there is an impaired renal function, in leukemia due to the considerable breakdown of cell nuclei with resulting increased metabolism of nucleoprotein, pneumonia, polycythemia and pernicious anemia (Varley, 1954). Such observations are in agreement with Wang et al., (2011) who described the contribution of the kidney to Romiplostim elimination. As Romiplostim dose is increased, more kidney damage occurs. Urinary excretion becomes a more prominent elimination route as Romiplostim dose increases.

The toxic effect of Rituximab on kidney is further confirmed by Borker and Choudary (2011) who stated that the US FDA has issued a black box warning on Rituximab in view of serious cardiovascular reactions, kidney failure, tumor lysis syndrome, severe mucocutaneous reactions, and progressive multifocal leukoencephalopathy, which were noticed after administration of the drug. Marangon et al., (2016) reported that infections represented the most frequently observed long-term complications with Rituximab in adults with primary immune thrombocytopenia (ITP): pneumonia, bronchial infection and urinary tract infection. Zhou $\boldsymbol{e t}$ al., (2015) reported that the most common adverse event was fever, which was mainly related to the upper respiratory, urinary tract, and gastrointestinal infection. There was an overrepresentation of rash, headache, stomachache, and chest congestion.

\section{CONCLUSION}

It can be concluded that co-administration of Romiplostim and Rituximab may constitute an alternative option for the treatment of immune thrombocytopenia whenever steroidal therapy becomes non effective. The safety of this regimen should be taken in consideration, so that a balance between the harmful effects and beneficial response could be attained. In the future studies, it is recommended to monitor the doses and duration of administration of the regimen of concomitant treatment for the management of immune thrombocytopenia

\section{REFERENCES}

ABOULAFIA, D. and VISHNU, P. 2016. Long-term safety and efficacy of Romiplostim for treatment of immune thrombocytopenia. Journal of Blood Medicine 99.

ABOULAFIA, D. AND VISHNU, P. 2016. Long-term safety and efficacy of Romiplostim for treatment of immune thrombocytopenia. Journal of Blood Medicine 99.

ARNOLD, D.M., DENTALI, F., CROWTHER, M.A., MEYER, R.M., COOK, R.J., SIGOUIN, C., FRASER, G.A., LIM, W. and KELTON, J.G. 2007. Systematic review: efficacy and safety of rituximab for adults with idiopathic thrombocytopenic purpura (Structured abstract). Annals of Internal Medicine 146: 25-33.

BERGMEYER, H.U. and HORDER, M. 1980. IFCC methods for the measurement of catalytic concentration of enzymes. 3. IFCC method for alanine aminotransferase. Journal of Clinical Chemistry and Clinical Biochemistry 18: 521-534.

BORKER, A. and CHOUDARY, N. 2011. Rituximab. Indian Pediatrics 48.

BUSSEL, J. B., HSIEH, L., BUCHANAN, G. R., STINE, K., KALPATTHI, R., GNARRA, D. J., HO, R. H., NIE, K., and EISEN, M. 2015. Long-Term Use of the Thrombopoietin-Mimetic Romiplostim in Children With Severe Chronic Immune Thrombocytopenia (ITP). Pediatric Blood Cancer 62: 208-13.

CHAPIN, J., LEE, C.S., ZHANG, H., ZEHNDER, J.L. and BUSSEL, J.B. 2016. Gender and duration of disease differentiate responses to rituximabdexamethasone therapy in adults with immune thrombocytopenia. American Journal of Hematology 91: 907-911.

CHUGH, S., DARVISH-KAZEM, S., LIM, W., CROWTHER, M.A., GHANIMA, W., WANG, G., HEDDLE, N.M., KELTON, J.G. and ARNOLD, D.M. 2015. Rituximab plus standard of care for treatment of primary immune thrombocytopenia: A systematic review and meta-analysis. The Lancet Haematology 2: e75-e81.

CONTIS, A., LAZARO, E., GREIB, C., PELlegrin, J.-L. and VIALLARD, J.-F. 2013. Romiplostim as early treatment for refractory primary immune thrombocytopenia. International Journal of Hematology 98: 520-524.

COOK, J.G.H. 1971. Creatinine assay in the presence of protein. Clinica Chemica Acta 32: 485-486.

CUKER, A. 2010. Toxicities of the Thrombopoietic Growth Factors. Seminars in Hematology 47: 289.

FOSSATI, P., PRENCIPE, L. and BERTI, G. 1980. Use of 3,5-dichloro-2-hydroxybenzenesulfonic acid/4aminophenazone chromogenic system in direct enzymic assay of uric acid in serum and urine. Clinical Chemistry 26: 227-231.

GARBER, J.C. 2010. Guide for The Care and Use of Laboratory Animals: Eighth Edition.

GAW, A., MURPHY, M., SRIVASTAVA, R., COWAN, R.A. and O'REILLY, D.S.J. 2013. Clinical 
Biochemistry E-Book: An Illustrated Colour Text Elsevier Health Sciences, Fifth edition.

HRUBAN, R.H., STERNBERG, S.S., MEYERS, P., FLEISHER, M., MENENDEZ-BOTET, C. and BOITNOTT, J.K. 1991. Fatal Thrombocytopenia and Liver Failure Associated with Carboplatin Therapy. Cancer Investigation 9: 263-268.

JANSSENS, A. 2012. Romiplostim for the treatment of primary immune thrombocytopenia. Expert Review of Hematology 5: 133-144.

KASHIWAGI, H. and TOMIYAMA, Y. 2013. Pathophysiology and management of primary immune thrombocytopenia. International Journal of Hematology 98: 24-33.

KING, P.D. and PERRY, M.C. 2001. Hepatotoxicity of Chemotherapy. The oncologist 6: 162-176.

KUTER, D.J., BUSSEL, J.B., LYONS, R.M., PULLARKAT, V., GERNSHEIMER, T.B., SENECAL, F.M., ALEDORT, L.M., GEORGE, J.N., KESSLER, C.M., SANZ, M. A, LIEBMAN, H. A, SLOVICK, F.T., DE WOLF, J.T.M., BOURGEOIS, E., GUTHRIE, T.H., NEWLAND, A., WASSER, J.S., HAMBURG, S.I., GRANDE, C., LEFRÈRE, F., ELI LICHTIN,A., TARANTINO,M. D., TEREBELO, H. R., VIALLARD, J.-F., CUEVAS,F. J., GO, R. S., HENRY, D. H., REDNER, R. L., RICE, L., SCHIPPERUS, M. R., GUO, D. M. and NICHOL, J. L. 2008. Efficacy of Romiplostim in patients with chronic immune thrombocytopenic purpura: a double-blind randomised controlled trial. Lancet 371: 395-403.

KUTER, D.J., MUFTI, G.J., BAIN, B.J., HASSERJIAN, R.P. and DAVIS W, R.M. 2009. Evaluation of bone marrow reticulin formation in chronic immune thrombocytopenia patients treated with Romiplostim. Blood 114: 3748-3756.

LIANG, Y., ZHANG, L., GAO, J., HU, D. and AI, Y. 2012. Rituximab for children with immune thrombocytopenia: A systematic review. PLoS ONE 7: Issue 5, e36698.

MARANGON, M.; VIANELLI, N.; PALANDRI, F.; MAZZUCCONI, M.G.; SANTORO, C.; BARCELLINI, W.; FATTIZZO, B.; VOLPETTI, S; LUCCHINI,E; POLVERELLI, N., CARPENEDO , M., ISOLA, M., FANIN, R. , ZAJA, F. 2016. Rituximab in immune thrombocytopenia: gender, age, and response as predictors of long-term response. Eur J Haematol 98.

MOUSSA, M.M. and MOWAFY, N. 2013. Preoperative use of Romiplostim in thrombocytopenic patients with chronic hepatitis $\mathrm{C}$ and liver cirrhosis. Journal of Gastroenterology and Hepatology 28: 335-341.

NEUNERT, C., LIM, W. and CROWTHER, M. 2011. The American Society of Hematology 2011 evidencebased practice guideline for immune thrombocytopenia. , Blood 117: 4190-4207.

PAGET, G.E. and BARNES, J.M. 1964. Toxicity tests. Evaluation of drug activities: pharmacometrics 1: 135165.

POHLEN, M., SARGIN, B., ZICHOLL, S., BISPING, G., MÜLLER-TIDOW， C., BERDEL，W.E., MESTERS, R. and KOSCHMIEDER, S. 2010. Combination of Romiplostim and rituximab: Effective therapy of severe immune thrombocytopenia. European Journal of Haematology 84: 362-364.

RAJ, A.B. 2017. Immune Thrombocytopenia : Pathogenesis and Treatment Approaches 5: 1-9.

SARIS, N.E. 1978. Revised IFCC method for aspartate aminotransferase. Clinical Chemistry 24: 720-721.

TAKABATAKE, T., OHTA, H., ISHIDA, Y.I., HARA, H., USHIOGI, Y. and HATTORI, N. 1988. Low Serum Creatinine Levels in Severe Hepatic Disease. Archives of Internal Medicine 148: 1313-1315.

TALKE, H. and SCHUBERT, G.E. 1965. Enzymatische Harnstoffbestimmung in Blut und Serum im optischen Test nachWarburg. Journal of Molecular Medicine 43: 174-175.

TIETZ, N.W., RINKER, A.D. and SHAW, L.M. 1983. IFCC methods for the measurement of catalytic concentration of enzymes Part 5. IFCC method for alkaline phosphatase (orthophosphoric-monoester phosphohydrolase, alkaline optimum, EC 3.1. 3.1). Journal of clinical chemistry and clinical biochemistry 21: 731 .

ULICH, T.R., DEL CASTILLO, J., YIN, S., SWIFT, S., PADILLA, D., SENALDI, G., BENNETT, L., SHUTTER, J., BOGENBERGER, J., SUN, D., SAMAL, B., SHIMAMOTO, G., LEE, R., STEINBRINK, R., BOONE, T., SHERIDAN, W.T. and HUNT, P. 1995. Megakaryocyte growth and development factor ameliorates carboplatin- induced thrombocytopenia in mice. Blood 86: 971.

VADHAN-RAJ, S. 2009. Management of ChemotherapyInduced Thrombocytopenia: Current Status of Thrombopoietic Agents. Seminars in Hematology 46: S26-S32.

VARLEY, H. 1954. Practical clinical biochemistry, 4th ed.

WANG, Y.M.C., SLOEY, B., WONG, T., KHANDELWAL, P., MELARA, R. and SUN, Y.N. 2011. Investigation of the pharmacokinetics of Romiplostim in rodents with a focus on the clearance mechanism. Pharmaceutical Research 28: 1931.

ZHOU, H., XU, M., QIN, P., ZHANG, H.Y., YUAN, C.L., ZHAO, H.G., CUI, Z.G., MENG, Y.S., WANG, L., ZHOU, F., WANG, X., LI, D.Q., BI, K.H., ZHU, C.S., GUO, C.S., CHU, X.X., WU, Q.C., LIU, X.G., DONG, X.Y., LI, J., PENG, J. and HOU, M. 2015. A multicenter randomized open-label study of rituximab plus rhTPO vs rituximab in corticosteroid-resistant or relapsed ITP. Blood 125: 1541-1547.

ZUFFEREY, A., KAPUR, R. and SEMPLE, J. 2017. Pathogenesis and Therapeutic Mechanisms in Immune Thrombocytopenia (ITP). Journal of Clinical Medicine 6: 16 .

How to cite this article:

Saeed H., Sayed H.M., Ramadan A. and Nahla S. Kotb. 2020. Toxic Interactions Of Romiplostim And Rituximab In Normal And Thrombocytopenic Rats. Journal of Applied Veterinary Sciences, 5(1): 1-10. DOI : https://dx.doi.org/10.21608/javs.2019.20470.1000 